\title{
NATURAL DISASTERS RISK - OFFICIAL STATEMENT AND AWARENESS OF WORKERS IN STARA ZAGORA REGION, BULGARIA
}

\author{
V. Slavova ${ }^{1}$, V. Ivanov ${ }^{1}$, P. Taleva-Rusinova ${ }^{2}$, J. Marinova $^{3}$, B. Parashkevova ${ }^{3}$, \\ G. Petrova ${ }^{3}$, M. Platikanova ${ }^{4}$ \\ ${ }^{1}$ Department of Neurology, Psychiatry and MDS, Faculty of Medicine, Trakia University, \\ Stara Zagora, Bulgaria \\ ${ }^{2}$ Department of Surgery, Neurosurgery, Urology and Anesthesiology, Faculty of Medicine, \\ Trakia University, Stara Zagora, Bulgaria \\ ${ }^{3}$ Department "Social Medicine and Health Care Management", Faculty of Medicine, \\ Trakia University, Stara Zagora, Bulgaria \\ ${ }^{4}$ Department "Hygiene, Infectious Diseases and Epidemiology", Faculty of Medicine, \\ Trakia University, Stara Zagora, Bulgaria
}

\begin{abstract}
Introduction: Disasters caused by natural phenomena often occur in Bulgaria. They cause a large number of dead, disappeared and medical losses in the zone of defeat. Social and economic consequences have a significant adverse effect on development and economic growth. For this reason reducing the risk of disaster situations and the readiness for protection are exclusively matter to sustainable development. Awareness of people at risk of natural disasters in the region in which they live and work is essential to reduce risk and increase readiness to protect.

Aim: Research and analysis of the preparedness of workers for dealing with disaster situations in Stara Zagora Region, taking in mind the awareness of respondents for the most risky natural disasters.

Material and methods: An empirical sociological study is conducted through direct group self administered questionnaire (SAQ) of 322 workers in various fields of the national economy in Stara Zagora Region. The survey was conducted from January to December 2016. The places of study were enterprises and companies in various industries in Stara Zagora Region, some of which are included in the list of sites of critical infrastructure in Bulgaria.

Results: Analysis of the results of the survey among workers in various fields of national economy in the Stara Zagora Region shows insufficient awareness about the risk of natural disasters as the majority of respondents indicate that there is no or little risk of them occurring.

Conclusion: Possible consequences in case of natural disasters require continuously and purposefully increase awareness about the most risky natural disasters in the area in which people live and work and remedies for protection and provision of first aid.
\end{abstract}

Key words: disaster, civil protection, natural disasters risk, workers' awareness about natural disasters risk, empirical sociological survey

\section{INTRODUCTION}

Disasters caused by natural phenomena often occur in Bulgaria. They cause a large number of dead, disappeared and medical losses in the zone of defeat. Social and economic consequences have a significant adverse effect on development and economic growth. For this reason reducing the risk of disaster situations

\footnotetext{
*Correspondence to: Vanya Slavova, Department of Neurology, Psychiatry and MDS, Faculty of Medicine, Trakia University, 11 Armeyska Str, 6000 Stara Zagora, Bulgaria, Phone: +35942664467, E-mail: vslavova71@yahoo.com
}

and the readiness for protection are exclusively matter to sustainable development. According to one of the main European Union policies concerning humanitarian aid and civil protection in disasters in the Republic of Bulgaria has received a Strategy for Disaster Risk Reduction. In the established strategy are defined four priorities for action, one of which concerns the knowledge and awareness of the population about the risk of different types of disasters - "Building a culture of disaster protection at all levels of government and in the society using the experience, training, 
research and innovation ". Insufficient public awareness of disaster risk reduction and response activities before, during and after disasters is a serious challenge. The measures implemented so far have been inconsistent and limited in scope.

\section{OBJECTIVE AND TASKS}

The aim of the study is to examine the risk of natural disasters in Stara Zagora Region, Bulgaria. To achieve the goal we set ourselves the following tasks:

1. To examine and analyze the risk of natural disasters in Stara Zagora Region, Bulgaria according existing official documents for the official opinion of this risk.

2. To examine and analyze the awareness of workers in various fields of the national economy in Stara Zagora Region, Bulgaria at risk of natural disasters.

\section{MATERIALS AND METHODS}

An empirical sociological study was conducted through direct group self - administered questionnaire (SAQ) of 322 workers in various fields of national economy in Stara Zagora Region, Bulgaria with a preponderance of manufacturing before the administrative sphere. The total number of respondents was 350 , of which 322 responded, response rate is $92 \%$. The survey was conducted from January to December 2016. The places of study were enterprises and companies in various industries in Stara Zagora Region, some of which from the list of sites of critical infrastructure in Bulgaria. Respondents were working in the fields of energetics, construction, engineering, manufacturing of rubber products and concrete structures.

The data and results presented in this research are part of a broad research study using a standard questionnaire containing 33 questions in seven main areas: the socio-demographic and professional characteristics of the respondents; awareness of the most risky natural and man-made disasters in Stara Zagora Region; acquired knowledge and skills for protection in the event of a disasters; acquired knowledge and skills for first aid; sources for acquiring knowledge and skills to protect and provide first-aid medical assistance in disasters; attitudes towards enhancing knowledge and skills for disaster protection and providing first-aid at the outbreak; willingness to participate in workplace action groups and volunteer teams to carry out rescue operations and provide first-aid disaster relief. In the present study were analyzed the respondents' awareness of the most risky natural disasters in Stara Zagora Region.
SLAVOVA V., et al. Questions about risk awareness of natural disasters allow respondents to assess this risk on a 4-degree scale (no risk, minimal risk, medium risk, high risk).

The survey was conducted at an appropriate time for workers, the time and location were agreed in advance and with the cooperation of employers.

The collection of empirical data was performed in compliance with the requirements of anonymity, voluntary participation and nonmaleficence in dealing with people.

For data collection was used statistical package IBM SPSS v.19. Data analysis was conducted applying descriptive statistics methods to summarize quantitative and qualitative variables (absolute frequencies, relative frequencies, cumulative frequencies).

\section{RESULTS AND DISCUSSION}

Socio-demographic characteristics of the respondents. The study includes 322 workers in different spheres of the national economy in the Stara Zagora Region.

Table 1. Socio-demographic characteristics of the respondents

\begin{tabular}{|c|l|}
\hline $\begin{array}{c}\text { Socio-demographic } \\
\text { characteristics }\end{array}$ & \multicolumn{1}{c|}{$\%(\mathbf{N})$} \\
\hline Age groups & $2,2 \%(7)$ \\
\hline up to 25 г. & $17,7 \%(57)$ \\
\hline from 25 to 34 г. 35 to 44 г. & $34,5 \%(111)$ \\
\hline from 45 to 54 г. & $32,9 \%(106)$ \\
\hline from 55 to 64 г. & $11,5 \%(37)$ \\
\hline over 64 г. & $1,2 \%(4)$ \\
\hline Sex & \\
\hline male & $66,1 \%(213)$ \\
\hline female & $33,9 \%(109)$ \\
\hline Education & \\
\hline without education & $0,6 \%(2)$ \\
\hline primary & $3,1 \%(10)$ \\
\hline secondary & $69,3 \%(233)$ \\
\hline college & $4,0 \%(13)$ \\
\hline university & $23,0 \%(74)$ \\
\hline
\end{tabular}

The average age of the respondents was 43.15 years (range 21 - 68 years, SD - 10.018). The minimum age is 21 years and the maximum age is 68 . The distribution by age groups shows that with the highest relative rate $34.47 \%$ are the persons aged 35-44 years, followed by the persons at the age 45-54 years - with a relative rate of $32.92 \%$. The age group 
25-34 years has a relative rate of $17.7 \%$ and the age between 55 and 64 years $-11.49 \%$. Under the age of 24 there are 7 persons $2.17 \%$ and over 65 years they are $4-1.24 \%$. The distribution by gender shows that 213 of the surveyed persons are men $-66.1 \%$ and women are $109-33.9 \%$, i.e. two thirds of the respondents are male. The distribution by education shows that the highest relative rate of those with completed secondary education are $69.3 \%$, followed by higher education graduates - $23.0 \%$ and college education $4.0 \%$. People with a low level of education are $3.7 \%$, including 10 respondents with primary and 2 without education. (Table 1)

Professional characteristics of the respondents - how long they have been working there and the position occupied by the respondents are examined. Of the surveyed group, $74.8 \%$ work in the manufacturing sphere of activity and $25.2 \%$ occupy an administrative position. The average time of working in the profession is 16.48 years (range from 1 - 46 years, SD - 10.717). The minimum time is 1 year and the maximum is 46 years. The distribution by groups shows that with the greatest relative rate - $27.3 \%$ are the respondents with work experience 11-25 years, followed by the respondents with work experience $6-10$ years - $23.0 \%, 21-30$ years $22.0 \%$. With work experience under 5 years are $16.5 \%, 31-40$ years $-10.2 \%$ and over 41 $0.9 \%$. (Table 2)

Table 2. Professional characteristics of the respondents

\begin{tabular}{|l|l|}
$\begin{array}{l}\text { Professional } \\
\text { characteristics } \\
\text { Occupied position }\end{array}$ \\
\hline manufacturing & $74,8 \%$ \\
\hline administrative & $25,2 \%(81)$ \\
\hline Work experience \\
\hline up to 6 г. \\
\hline from 6 to 10 years & $16,5 \%(53)$ \\
\hline from 11 to 20 years & $23,0 \%(74)$ \\
\hline from 21 to 30 years & $22,0 \%(78)$ \\
\hline from 31 to 40 years & $10,2 \%(33)$ \\
\hline \hline over 40 years & $0,9 \%(3)$ \\
\hline \hline
\end{tabular}

Awareness of the riskiest natural disasters in Stara Zagora. According to The Plan for Disaster Protection of Stara Zagora region, updated by Order RD-09-185/18.04.2012 of the Governor, possible natural disasters in the region are: earthquakes, floods, storms, hurricanes, forest and field fires etc.(4).
SLAVOVA V., et al. Earthquakes. Seismic activity in Stara Zagora region is determined by the Alpine-Himalayan seismic belt and mostly by Mariska seismic zone, which covers the middle flow of the Maritsa river. According to the final report on the seismic zoning of Bulgaria, following the requirements of Eurocodes 8 in the area there is a potential risk of earthquakes with magnitude 5,5 - 6,5 on the Richter scale and intensity VIII / IX in Medvedev-SponheuerKarnik scale (MSK). The estimated seismic zoning and expected seismic impacts are periods of repeatability between 100, 1000 and 10000 years. According optimal variant for 1000 years, the $98 \%$ of the area of the region, earthquakes are to be subjected to an intensity of VII and a higher level, of which have been: VII - $51 \%$, VIII - 28\%, IX and higher $-19 \%$. On the territory of Stara Zagora the assessment of the situation in the event of an earthquake of VIII-IX degree in MSK-64 are expected irrevocable 29504 and 26295 medical losses (4).

In our study, the largest share respondents who identify the risk of earthquakes as small $41.61 \%$. No risk for $27.64 \%$, there is a moderate level of risk for $24.22 \%$ and high risk - for only 6,52\% of the respondents. (Figure 1)

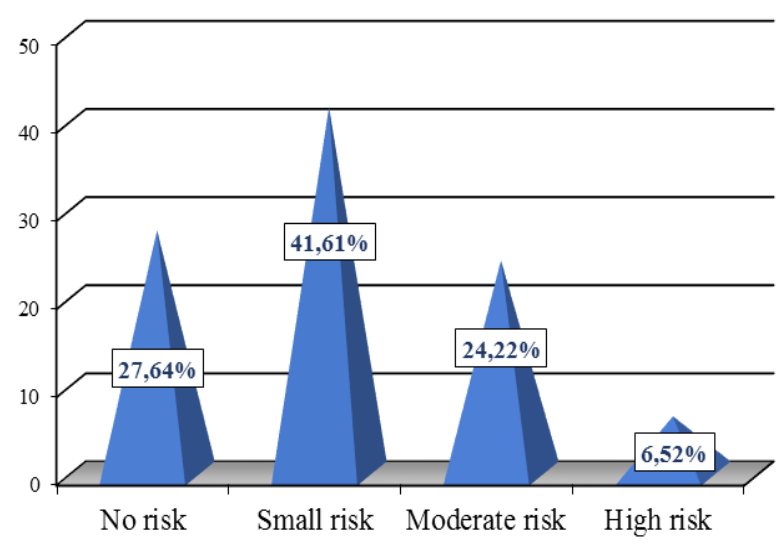

Figure 1. Risk of earthquakes

Floods. Assessment and management of flood risks in Bulgaria is based on The European Union Floods Directive 2007/60/EU on the assessment and management of flood risks. The EU Directive is in force since 26.11.2007 and is transposed into national legislation by amending the Law on Waters in August, 2010. The Directive it is required the Member States to implement approach to reducing flood risks in three stages (5):

- Preliminary assessment of flood risk where to be defined so called Areas with potential significant flood risk (APSFR);

- Developing a flood hazard maps and flood risk maps for each APSFR;

- Development of flood risk management plans for each APSFR. 
Ministry of Environment and Water of Bulgaria separates fourth area of water management - The Danube, The Black Sea, the East White Sea and The West White Sea in each is individually made a preliminary assessment of risk and are determined APSFR (6).

Stara Zagora region falls in 5 areas with potential significant flood risk in the East White Sea region:

- APSFR "Tunja" (Koprinka - Jrebchevo) with a length of $72 \mathrm{~km}$;

- APSFR "Tunja - Kalofer" with a length of $27 \mathrm{~km}$;

- APSFR "Sazliyka" with a length of $75 \mathrm{~km}$;

- APSFR "Maritza - Dimitrovgrad" with a length of $59 \mathrm{~km}$;

- APSFR "Maritza" - Plovdiv length of 114 $\mathrm{km}$.

Among the larger towns in the area falling directly into these APSFR are Kazanlak, Muglizh, Nikolaevo, Pavel banya, Galabovo, Radnevo.

On the territory of Stara Zagora there is a probability of local floods that do not significantly affect the functioning of the national economy and threaten the lives of the population. In the event of floods in the region it is created a complex environment of restricted territory (4).

The analysis of the results of our study showed that the largest share respondents determine the risk of floods as small - $35.4 \%$. No risk for $29.81 \%$, there is a moderate level of risk for $25.47 \%$ and high risk - for only $9,32 \%$ of the respondents. (Figure 2)

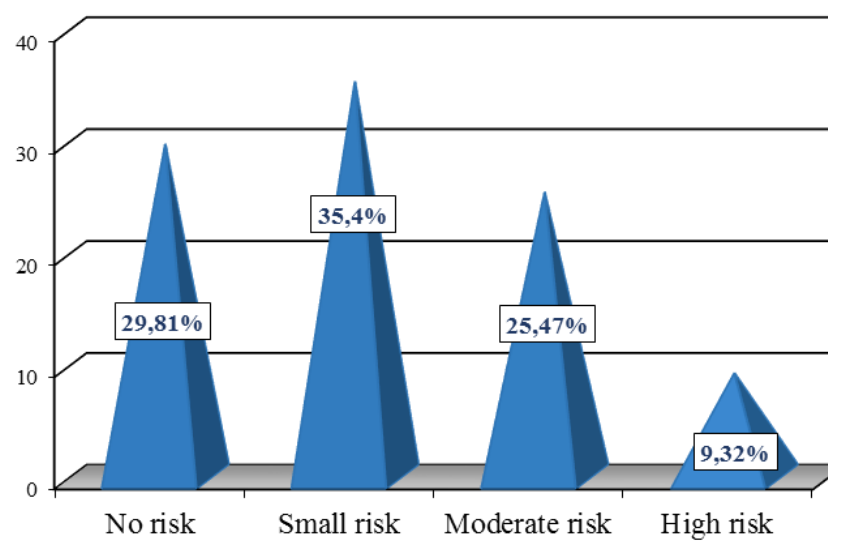

Figure 2. Risk of floods

Storms, hurricanes. The analysis and assessment of the risk of storms, hurricanes, snowdrifts and icing in Stara Zagora shows that especially during the winter months it is possible to occur such disasters, thus creates a state of emergency in one or more
SLAVOVA V., et al. municipalities or throughout the region. There are possible serious consequences such as power cut, stopping the communication links and water supply of settlements; disruption of transport provision of the population in municipal and national road network; disruption to supply the population with food, drinking water and materials for heating; letting humans and animals without shelter, food and drinking water in settlements, huts and along the roads of the area, possible road traffic accidents (7).

The analysis of the survey data shows that the risk of storms, hurricanes and snowdrifts is defined as less than the majority of the respondents - $46.89 \%$. Average level of risk is determined by $14,91 \%$. For more than a third of respondents $-34.16 \%$ no risk, but the risk is $4.04 \%$ higher. (Figure 3)

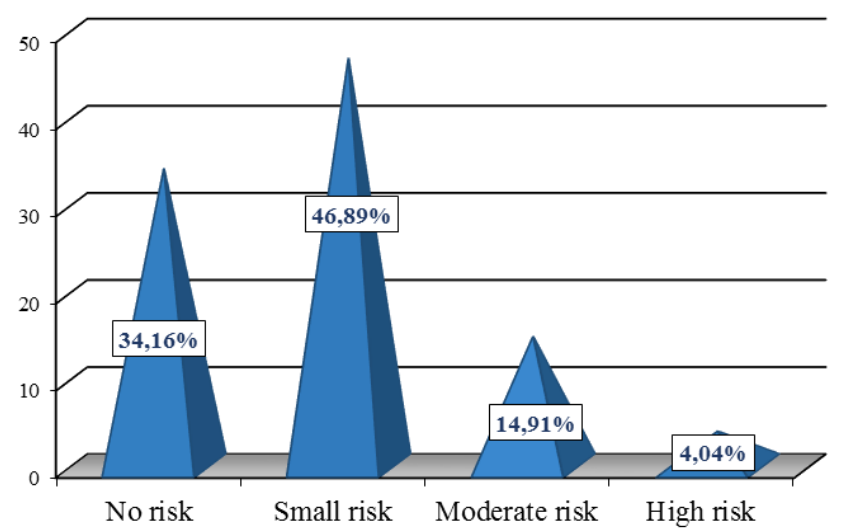

Figure 3. Risk of storms, hurricanes

Landslides. Landslides are one of the major hazards that form the geodynamic potential danger. So far in Bulgaria has more than 900 landslides in 350 settlements with a total area of 20 thousand Hectares. Landslides are not evenly spread throughout the country. They are concentrated in specific areas, characterized by a specific geological and tectonic structure. For a preliminary assessment of the distribution of landslides and landslide danger in Bulgaria are composed a catalog and a map of landslides. According to the currently available data on the territory of Stara Zagora there are no registered landslides (8).

Knowledge and awareness of the surveyed individuals in our study corresponds to the available data - according to $61,8 \%$ no risk of landslides. Nearly two-thirds believe there is a minimal risk - $31,06 \%$ and $7,14 \%$ only determine the level of risk as medium $(6.21 \%)$ and high $(0.93 \%)$. (Figure 4) 


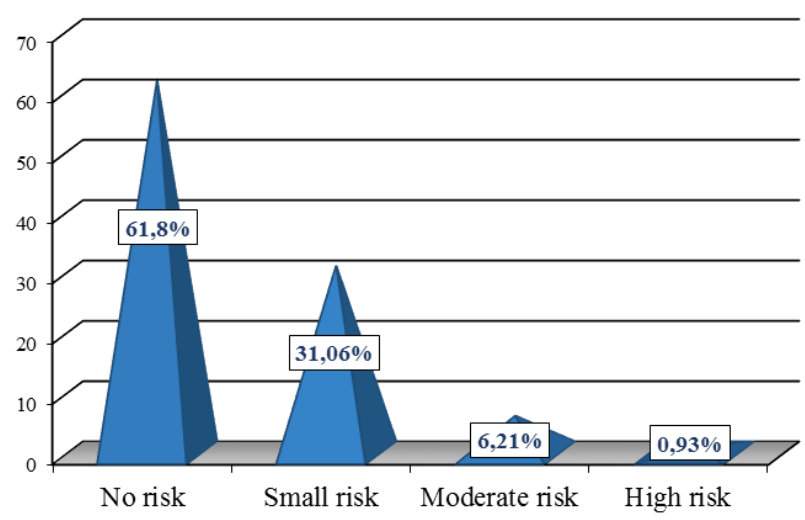

Figure 4. Risk of landslides

Fires. The largest is the risk of fires in industrial objects and critical infrastructure, forests and agricultural areas. Fires in industrial objects and critical infrastructure leads to a threat to life and health of many people, property damage and environmental pollution. Escalation of the situation can be expected from prolonged droughts and extreme temperatures or intentional acts. The relife of the Bulgarian land is such that part of the territory is mountainous - woody, forests dominated and there is the first and second degree of fire danger and there are conditions for the occurrence of large forest fires. Fire problematic areas are the districts of Haskovo, Stara Zagora, Blagoevgrad, Sofia, Pazardzhik, Plovdiv, Yambol and Burgas, where over the past 10 years a large number of fires grown into disasters have arisen that have developed in large disasters on large areas and inflicted major damage (4).

Forests in Stara Zagora with a high risk Class 1 /coniferous/ cover an area of 86205 ha, representing $50.25 \%$ of the entire forest. Field areas in high-risk occupy 110000 ha.

The results of our study show that the largest share respondents who identify the risk of fires as small are $34.16 \%$. High level of risk is $27.33 \%$, moderate - to $20.81 \%$. No risk of $17.7 \%$. (Figure 5)

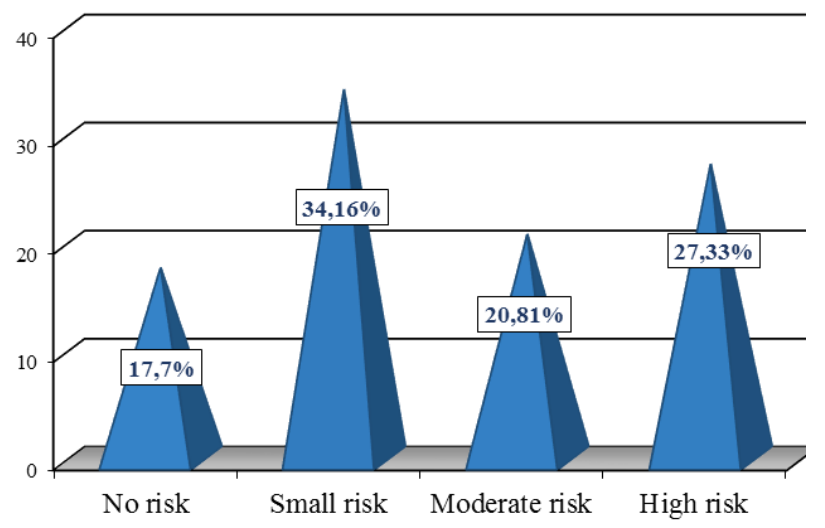

Figure 5. Risk of fires

\section{CONCLUSIONS}

SLAVOVA V., et al.

Analysis of the results of the survey among workers in various fields of national economy in the Stara Zagora Region shows insufficient awareness about the risk of natural disasters as the majority of respondents indicate that there is no or little risk of them occurring. Possible consequences in case of natural disasters require continuously and purposefully increase awareness about the most risky natural disasters in the area in which people live and work and remedies for protection and provision of first aid. To raise public awareness is necessary to provide easily understandable and accessible information on disaster risk and protecting the population. It is essential the effective use of media, internet and all existing means of communication.

\section{REFERENCES}

1. Alexiev R., Survival in disaster situations. Sofia, NSA „Vassil Levski” NSAPRESS, 3, 2004.

2. A strategy for reducing the risk of disasters from 2014 to 2020 in Bulgaria, Sofia, 2013.

3. Humanitarian Aid and Civil Protection, European Union, Brussels, 2013.

4. Annual Report on the European Union's humanitarian aid and civil protection and their implementation in 2011, COM (2012) 489 final, Brussels, 06.09.2012.

5. Slavova V., Dimitrova D., Ivanov V., Parashkevova B., Vasileva A., Platikanova M., State policy for training the population for protective actions during disastrous situations. International research journal, 4(46):122-124, 2016.

6. Todorova D., Etova R., Awareness and readiness of the population for disaster situations, Part I. Health and Science, IV, 3 (015), 26-30, 2014.

7. Etova R., Todorova D., Spasova Z., Awareness and readiness of the population for disaster situations, Part II. Health and Science, 1, 12-16, 2016.

8. Todorova D., Mihailova Ts., Etova R., Garov Sv., Management of risk situation. Journal of IMAB, Jul-Sept, 22(3):11981201, 2016.

DOI:HTTP://DX.DOI.ORG/10.5272/JIMA B. 2016223.1198

9. Plan for Disaster Protection of Stara Zagora, Order RD-09-185 / 18.04.2012 of the District Governor of Stara Zagora, 2012.

10.Directive 2007/60/EC of the European Parliament and of the Council of 23 October 2007 on the assessment and management of flood risks, Official Journal of the European Union, L 288/27, 6.11.2007. 
11.Etova R., Population medical care management and flood relief efforts in the middle course of the Maritza River, Dissertation for pronouncement PhD, 2016.

12.National Plan for Disaster Protection, Council of Ministers, Sofia, 2010.
13. Annual Plan for 2014 to implement the National Program for Disaster Protection (2014-1018), Sofia, 2013.

14.Annual Plan for 2013 to implement the National Program for Disaster Protection (2009-1013), Sofia, 2012. 